The number who gave this as a reason for disliking the system was, however, comparatively small, though unfavourable comments indicated a feeling of dependence upon others and feelings of frustration.

About $40 \%$ of the men compared their own system of payment with other systems, sometimes favourably and sometimes unfavourably.

Supervisors were also asked for their views. While financial incentives were accepted as the most important, and indeed perhaps the only incentive, in each factory most supervisors mentioned more than one incentive. In Factory $\mathbf{A}$, where the number of named incentives was highest, the managing director kept himself informed of the needs and aspirations of the workers, and did his utmost to provide for the security, opportunity, welfare, and social and recreational activities that they required. In this factory, $40 \%$ of the workers spoke of this person as being responsible for the things they liked.

The final discussion deserves to be read in full. Much experience and sense is packed into the last six pages. With characteristic modesty the report ends by suggesting that " even a limited survey of the type described shows what workers like and dislike and to that extent it can be used as a guide to managerial policy and practice". There are pitfalls in the introduction of almost any system of payment. "The main thing is to make the worker feel that he is getting a square deal, and if this is done he will usually give a square deal in return."

How important it is that this admirable study should be regarded as the beginning and not the end of researches into attitudes to factory work. Management should at last recognize that the social or industrial psychologist has a real contribution to make in providing facts, the understanding of which is essential if a sound management policy is to emerge.

\section{The British Occupational Hygiene Society}

An ordinary scientific meeting of the British Occupational Hygiene Society was held at the London School of Hygiene and Tropical Medicine on February 13, 1957. The Society's president, Dr. C. G. Warner, was in the chair and about $\mathbf{4 0}$ members and their guests attended the meeting. Five communications were presented to the meeting on a variety of subjects of interest to members and each was fully discussed. Brief synopses of these communications are given below.

\section{Inert-gas Metal-arc Welding}

Joan Bedford, P. J. R. Challen, and D. E. Hickish, London School of Hygiene and Slough Industrial Health Service, outlined the inert-gas-shielded method of welding aluminium and the chemical hazards arising from its use. An industrial hygiene investigation had been carried out in a workshop where this method is employed in the fabrication of aluminium containers. Air sampling was carried out for ozone, trichloro-ethylene, and phosgene, and concentrations of ozone were found to exceed the maximum allowable concentration. The toxicity of ozone was reviewed and clinical findings presented. Preliminary tests of a system of local exhaust ventilation for the automatic welding machines were described.

\section{Heated Floors and Comfort}

F. A. Chrenko, Medical Research Council, described experiments conducted with three women and five men who wore their usual shoes and indoor clothing. In a given experiment which lasted for one hour a subject either sat with his feet on a heated floor or walked slowly to and fro. Altogether, about 380 experiments were made on sitting subjects and 480 experiments on walking subjects.

The air temperatures in these experiments ranged from $58^{\circ}$ to $76^{\circ} \mathrm{F}$. and averaged $68^{\circ} \mathrm{F}$. In any single experiment the drift in air temperature was negligible. High floor-surface temperatures produced discomfort because the feet, and especially the soles, became uncomfortably warm, and this was shown by high skin temperatures. A skin temperature of $93.6^{\circ} \mathrm{F}$. on the sole of the foot was associated with a $50 \%$ incidence of discomfort. The feet did not become uncomfortably warm until the floor temperature exceeded $77^{\circ} \mathrm{F}$., and it is concluded that in a room maintained at a normal temperature the floor temperature should not exceed $77^{\circ} \mathrm{F}$., or preferably $75^{\circ} \mathrm{F}$. Tolerance of the subjects to heated floors was found to vary with the temperature of the air so that a higher floor temperature could be tolerated as the air temperature was lowered. Mercury-in-rubber strain gauges were used to detect any changes in girths of the ankle and instep when subjects were exposed to a heated floor, but the results were indeterminate. The skin 
temperature of the sole at which the incidence of discomfort began to rise rapidly was about the same as that at which a rapid increase in blood flow through the foot might be expected. The results of the present experiments were compared with the conclusions reached in some earlier investigations. The results of these experiments were published in full in a recent paper in this Journal $(14,13,1957)$.

\section{A Universal Entraining Unit for Use in the Determination of Atmospheric Contamination}

K. W. Holmes, J. Mackay, and R. E. Wilson, Ministry of Supply, described and demonstrated an apparatus which has been constructed for entraining samples of contaminated air without recourse to normal services, such as water or electricity. This apparatus also measured the volume of air passing through the entraining unit.

\section{Beryllium Monitoring}

A. H. Gillieson, Atomic Energy Research Establishment, briefly introduced the nature of and analytical problems presented by the hazard of air-borne beryllium compounds. Two methods for the detection and estimation of beryllium or its compounds, as dust or aerosols, in laboratory or plant atmospheres were outlined. Both methods were spectrographic, the first being a development of the normal filter collection procedure for rapid spectrographic analysis; the second applied a relatively new direct recording spectrographic technique whereby an instantaneous indication of the beryllium content of the sampled air is given. Both methods have been developed by the Research Group of the U.K.A.E.A. by two different teams of spectrographers. The first method is the more accurate, but sampling time being of necessity relatively long the average beryllium concentration over the sampling period is measured. The second method is inherently less accurate because of its sensitivity to particle size, but it gives in practice an almost instantaneous ( 20 seconds) indication of the presence of an air-borne beryllium hazard.

\section{The Thermal Environment in Non-ferrous Foundries}

W. B. LAWRIE, Ministry of Labour and National Service, and D. Turner, Medical Research Council, reported measurements of the various factors in the thermal environment made in a number of typical diecasting foundries in an attempt to assess the severity of any thermal stress imposed on the foundrymen and to suggest ways in which this stress might be reduced. The degree of stress was found to vary markedly from place to place, being largely dependent upon the melting procedures in use. It was apparent that many conventional furnaces were thermally inefficient. An oil-fired furnace was designed in which the thermal efficiency was much increased, resulting in much cooler working conditions in the foundry. Some of the results obtained, and a full description of the reverberatory furnace, have been published.*

* Turner, D., Lawrie, W. B., Eyden, A., and Edwards, A. (1956). Metal Ind. (Lond.), 88, 393, 413. (See also p. 177 of this issue.)

\section{BOOK REVIEWS}

Symposium of Tuberculosis. Edited by F. R. G. Heaf. (Pp. xvi $+755 ; 78$ plates, 54 figures. $£ 5$ 5s.) London: Cassell. 1957.

This book is a collection of essays of varying style and merit forming a valuable textbook with the emphasis in the right places. The editor, Professor Heaf, states in the foreword that the book is particularly directed towards helping those who work in countries where tuberculosis is still a major health problem. But all except the most complacent in any country can profit from it. Ideas on treatment change so rapidly at present that it is impossible for the critical physician to teach dogma; and to write didactically but still be convincing and clear is very difficult. It is, therefore, not a criticism of the authors to say that the sections on the treatment of pulmonary tuberculosis are not likely to be as useful as some other parts of the book. The deliberate emphasis on prevention and the practical details of chest clinic routine and public health practice is refreshing after a decade of preoccupation with therapeutic advances and the widening clinical interests of the chest specialist. The relatively neglected subject of the relationship between tuberculosis and the industrial environment is well reviewed by Dr. Alice Stewart; and Dr. P. V. Benjamin of India contributes a valuable chapter on the problems of tuberculosis control in the economically underdeveloped countries. The references given with each chapter are useful: but they would be more so if the practice of giving the titles of articles had been adopted. The purpose of a reference in a text-book is not only to authenticate a statement in the text but to show the reader where he can find more details of the subject; and the title of the paper is necessary to show him the scope of the work referred to.

\section{J. R. Bignall}

Ministry of Fuel and Power: Pneumoconiosis in the Mining and Quarrying Industries. Digest of Statistics, 1955. (Pp. iv + 20. 3s.) London: H.M.S.O. 1956.

This publication is the fifth of an annual series in which statistics relating to pneumoconiosis (including silicosis and asbestosis) are assembled. Although with few exceptions the tables are derived from the records of the Ministry of Pensions and National Insurance, their scope is limited to the mining and quarrying industries, whose health and welfare are the concern of the Ministry of Fuel and Power. This purely administrative distinction means that the tables give no information about some $17 \%$ (in 1955) of the cases of pneumoconiosis newly diagnosed, of which more than half come from the pottery and foundry industries. (Ministry of Pensions and National Service. Annual Report, 1955. H.M.S.O. 1956.) 